\title{
Directed evolution improves the enzymatic synthesis of L-5-hydroxytryptophan by an engineered tryptophan synthase
}

Xu Lisheng ( $\nabla$ xulisheng111@163.com )

Suzhou University

Tingting Li

Suzhou University

Ziyue Huo

Suzhou University

Qiong Chen

Suzhou University

Qiuxia Xia

Suzhou University

Bianling Jiang

Suzhou University

\section{Short Report}

Keywords: L-5-hydroxytryptophan, tryptophan synthase, directed evolution

Posted Date: June 1st, 2021

DOI: https://doi.org/10.21203/rs.3.rs-174454/v1

License: (1) This work is licensed under a Creative Commons Attribution 4.0 International License.

Read Full License 


\section{Abstract}

L-5-Hydroxytryptophan is an important amino acid that is widely used in food and medicine. In this study, L-5-hydroxytryptophan was synthesized by a modified tryptophan synthase. A direct evolution strategy was applied to engineer tryptophan synthase from Escherichia coli to improve the efficiency of L-5hydroxytryptophan synthesis. Tryptophan synthase was modified by error-prone PCR. A high activity mutant enzyme (V231A/K382G) was obtained by a high-throughput screening method. The activity of mutant enzyme $(\mathrm{V} 231 \mathrm{~A} / \mathrm{K} 382 \mathrm{G})$ is 3.79 times higher than that of its parent, and $k_{\text {cat }} / K_{\mathrm{m}}$ of the mutant enzyme $(\mathrm{V} 231 \mathrm{~A} / \mathrm{K} 382 \mathrm{G})$ was $4.36 \mathrm{mM}^{-1} \cdot \mathrm{s}^{-1}$. The mutant enzyme $(\mathrm{V} 231 \mathrm{~A} / \mathrm{K} 382 \mathrm{G})$ reaction conditions for the production of L-5-hydroxytryptophan were $100 \mathrm{mmol} / \mathrm{L} \mathrm{L}$-serine at $\mathrm{pH} 8.5$ and $35^{\circ} \mathrm{C}$ for $15 \mathrm{~h}$, reaching a yield of L-5-hydroxytryptophan of $86.7 \%$. Directed evolution is an effective strategy to increase the activity of tryptophan synthase.

\section{Introduction}

L-5-Hydroxytryptophan is a special amino acid found in both plants and animals. L-5-Hydroxytryptophan increases brain serum concentrations and brain melatonin levels, improves symptoms of spinal cord atrophy and promotes sleep [1]. L-5-Hydroxytryptophan has a good effect on the treatment of depression. Exogenous L-5-hydroxytryptophan crosses the blood-brain barrier, increasing the concentration of serotonin in the brain and reducing the production of cytokines in the body, thus improving depression [2-4]. L-5-Hydroxytryptophan was prepared by plant extraction and biosynthesis. L-5-Hydroxytryptophan from Ghana seeds was adsorbed and separated by ion-exchange resin. The yield of L-5hydroxytryptophan was 7.95\% [5]. L-5-Hydroxytryptophan was extracted from Ghana seeds by hydrothermal reflux extraction, alcohol reflux extraction and ultrasonic water extraction, and L-5hydroxytryptophan was also extracted from cohosh [6]. L-5-Hydroxytryptophan was prepared by tryptophan hydroxylase, which promoted the synthesis of L-5-hydroxytryptophan by metabolic engineering $[7,8]$. The yield of L-5-hydroxytryptophan prepared by the plant extraction method was lower compared with the yield prepared by the biosynthesis method, and the enzymatic reaction was specific with fewer by-products. Chemical synthesis method was easy to bring pollution to the environment. Enzymatic synthesis is an effective strategy to synthesize short-chain flavor esters, phytosteryl lipoate, Lo-galloylglycerol [9-11]. Directed evolution has been widely used in the field of drug synthesis [12, 13]. Directed evolution can promote the enzymatic activity of lipase, xylanase, a-galactosidases, monoamine oxidase and nitrilase [14-19]. L-tryptophan and S-phenyl-L-cysteine were synthesized by tryptophan synthase of Escherichia coli k-12, and it was found that tryptophan synthase has the potential to synthesize L-tryptophan and its derivatives [20-22]. In this study, directed evolution of tryptophan synthase was performed by error-prone PCR. L-5-Hydroxytryptophan was synthesized by L-serine and 5hydroxyindole using tryptophan synthase as the catalyst. This provides a new strategy for the enzymatic synthesis of L-5-hydroxytryptophan.

\section{Materials And Methods}




\section{Chemicals}

L-Serine, 5-hydroxyindole, peptone, and yeast extract were purchased from Alighting Biochemical Technology Co. Ltd. (Shanghai, China). Isopropyl-ß-D-thiogalactoside, pyridoxal phosphate (PLP) were purchased from Sangon Biotech Co., Ltd. (Shanghai). Other chemicals were analytical reagents. Error-prone PCR mutant library

According to the trpB sequence of E. colik-12 tryptophan synthase (ID: 945768) and the MCS site of the pETDuet-1 vector published by the NCBI, two primers were designed using Primer Premier 5.0. Ncol and $E c o R I$ were introduced at the $5^{\prime}$ end of the upstream and downstream primers, respectively. The primers were synthesized by Shanghai Yingjun Biotechnology Co., Ltd.

5'-CCCCATATGACAACATTACTTAAC-3', 5'-CCCGAATTCTTAACTGCGCGTTT-3'

Random mutations were introduced into the trpBA gene using the Trans EasyTaq DNA polymerase kit. The PCR system and PCR procedure are described in the instructions.

\section{Screening of tryptophan synthase}

A single colony of mutant strain was selected from the petri dish and inoculated into a 96-well shallow orifice plate with $1 \mathrm{~mL} L B$ liquid medium $\left(35^{\circ} \mathrm{C}\right)$. Isopropyl- $\beta$-D-thiogalactoside and PLP were added to each well of 96 -well shallow orifice plate at $18^{\circ} \mathrm{C}$. The fermentation mutant strain was centrifuged after induction $\left(4^{\circ} \mathrm{C}, 4000 \mathrm{r} \cdot \mathrm{min}^{-1}, 10 \mathrm{~min}\right)$. L-Serine and 5 -hydroxyindole were added to the 96 -well shallow orifice plate $\left(37^{\circ} \mathrm{C}, 30 \mathrm{~min}, 200 \mathrm{r} \cdot \mathrm{min}^{-1}\right)$. The absorbance value at $290 \mathrm{~nm}$ was measured by ELISA.

\section{Purification of tryptophan synthase}

The engineered bacteria of tryptophan synthase were crushed by ultrasonication $\left(600 \mathrm{~W}, 10 \mathrm{~min}, 0^{\circ} \mathrm{C}\right)$. The crude enzyme was centrifuged at $5000 \mathrm{r} \cdot \mathrm{min}^{-1}$ for $10 \mathrm{~min}$. The supernatant was collected to obtain the crude tryptophan synthase enzyme liquid. The supernatant of tryptophan synthase were purified by Ni-NTA column using the method reported in the literature [23].

\section{Determination of enzymatic activity}

Tryptophan synthase activity was determined by the L-5-hydroxytryptophan concentration. The enzyme reaction conditions for the production of L-5-hydroxytryptophan were $100 \mathrm{mmol} / \mathrm{L} \mathrm{L}$-serine at pH 8.5 and $35^{\circ} \mathrm{C}$ for $15 \mathrm{~min}$. The conversion at this time point was $17 \%$. The concentration of L-5-hydroxytryptophan was determined by an amino acid analyser (L-8900, Japan). Resin column was sulfonic acid type cationic resin column $(4.6 \mathrm{~mm} \times 60.0 \mathrm{~mm})$. Column temperature was $57.0^{\circ} \mathrm{C}$. Reactor temperature was $130{ }^{\circ} \mathrm{C}$. The flow rate of pump A (elution solution) was $0.40 \mathrm{~mL} / \mathrm{min}$. The flow rate of $\mathrm{B}$ (ninhydrin solution) was $0.35 \mathrm{~mL} / \mathrm{min}$, and the injection volume was $20 \mu \mathrm{L}$. The detection wavelength was $570 \mathrm{~nm}$ and $440 \mathrm{~nm}$.

\section{Determination Of Kinetic Parameters}


Determination of kinetics parameters was carried out using five L-serine concentrations $(0.1 \mathrm{mmol} / \mathrm{L}, 0.2$ $\mathrm{mmol} / \mathrm{L}, 0.3 \mathrm{mmol} / \mathrm{L}, 0.4 \mathrm{mmol} / \mathrm{L}$ and $0.5 \mathrm{mmol} / \mathrm{L}$ ). Kinetics parameters of tryptophan synthase were obtained through the Lineweaver-Burk methodology.

\section{Preparation of L-5-hydroxytryptophan}

The optimum reaction conditions for L-5-hydroxytryptophan synthesis catalysed by tryptophan synthase were studied. The effects of temperature, $\mathrm{pH}$ and substrate concentration on tryptophan synthase were investigated. L-5-Hydroxytryptophan was synthesized under the optimal reaction conditions. The optimal conditions and reaction volume for L-5-hydroxytryptophan preparation were L-serine $100 \mathrm{mmol} / \mathrm{L}, 35^{\circ} \mathrm{C}$, $\mathrm{pH} 8.5$ and $1000 \mathrm{ml}$. The reaction system $(1000 \mathrm{ml})$ containing $10.5 \mathrm{~g} \mathrm{~L}$-serine, $13.3 \mathrm{~g}$ 5-hydroxyindole, $0.01 \mathrm{~g}$ pyridoxal phosphate and $0.1 \mathrm{~g}$ tryptophan synthase. L-5-hydroxytryptophan was analyzed with an FT-IR Spectrometer ( Gangdong Sci \& Tech. Co., Ltd., Tianjing, China). All treatment of L-5hydroxytryptophan synthesis catalysed by tryptophan synthase were repeated for three times. SPSS 22.0 was used to analysis of experimental data.

\section{Results And Discussion}

\section{Mutant of tryptophan synthase}

Random mutant library of tryptophan synthase was constructed by error-prone PCR. The mutation rate of error-prone PCR was $1.2 \%$ in this study. The highly enzymatic activity of mutant V231A/K382G was obtained from screening 12,000 mutant strains of tryptophan synthase. The activity of mutant enzyme $(\mathrm{V} 231 \mathrm{~A} / \mathrm{K} 382 \mathrm{G})$ is 3.79 times higher than that of its parent (Fig. 1$)$, and $k_{\text {cat }} / K_{\mathrm{m}}$ of the mutant enzyme (V231A/K382G) was $4.36 \mathrm{mM}^{-1} \cdot \mathrm{s}^{-1}$ (Table 1). The specific activity of WT was $3876 \mathrm{U} / \mathrm{mg}$. These results indicated that sites 231 and 382 were the key sites affecting the activity of trpBA. The growth of the wildtype strain and V231A/K382G strain was observed under a microscope. There was no difference in morphology between the four strains in Fig. 2 (Wild-type strain; V231A/K382G; D381G; T319S) . 
Table 1

Kinetic parameters of tryptophan synthase and its mutants.

\begin{tabular}{|lllll|}
\hline Mutations & $K_{\mathrm{m}}(\mathrm{mM})$ & $k_{\text {cat }}\left(\mathbf{s}^{-1}\right)$ & $k_{\text {cat }} / K_{\mathrm{m}}\left(\mathrm{mM}^{-1} \cdot \mathrm{s}^{-1}\right)$ & Fold change over WT \\
\hline WT & $0.33 \pm 0.12$ & $0.38 \pm 0.13$ & $1.15 \pm 0.09$ & 1 \\
\hline V231A/K382G & $0.28 \pm 0.06$ & $1.22 \pm 0.08$ & $4.36 \pm 0.11$ & 3.79 \\
\hline D381G & $0.31 \pm 0.11$ & $0.41 \pm 0.09$ & $1.32 \pm 0.08$ & 1.14 \\
\hline P257R & $0.21 \pm 0.03$ & $0.10 \pm 0.02$ & $0.47 \pm 0.01$ & 0.41 \\
\hline H313F & $0.29 \pm 0.07$ & $0.32 \pm 0.10$ & $1.10 \pm 0.05$ & 0.96 \\
\hline L80H & $0.25 \pm 0.04$ & $0.29 \pm 0.07$ & $0.86 \pm 0.07$ & 0.75 \\
\hline N64G/S352P & $0.23 \pm 0.03$ & $0.16 \pm 0.02$ & $0.69 \pm 0.06$ & 0.60 \\
\hline T319S & $0.30 \pm 0.07$ & $0.32 \pm 0.10$ & $1.06 \pm 0.04$ & 0.92 \\
\hline A67M & $0.21 \pm 0.03$ & $0.12 \pm 0.02$ & $0.57 \pm 0.01$ & 0.49 \\
\hline
\end{tabular}

\section{Effects of temperature, $\mathrm{pH}$ and L-serine on the enzymes}

The reaction activity of the mutated enzyme and parental enzyme at $25^{\circ} \mathrm{C}, 30^{\circ} \mathrm{C}, 35^{\circ} \mathrm{C}, 40^{\circ} \mathrm{C}, 45^{\circ} \mathrm{C}, 50^{\circ} \mathrm{C}$ was investigated. The optimal temperature of the mutated enzyme $\mathrm{V} 231 \mathrm{~A} / \mathrm{K} 382 \mathrm{G}$ and the parental enzyme was approximately $35^{\circ} \mathrm{C}$ (Fig. $3 \mathrm{~A}$ ). The relative activity of mutant enzyme V231A/K382G was $100 \%$ and the relative activity of the parent enzyme was $26 \%$. Under reactions at $\mathrm{pH} 6,6.5,7,7.5,8,8.5,9$, $9.5,10$, the relative activity of mutant enzyme $\mathrm{V} 231 \mathrm{~A} / \mathrm{K} 382 \mathrm{G}$ was $100 \%$ while the relative activity of the parent enzyme was $24 \%$ at $\mathrm{pH} 8.5$. The activity of the parent enzyme was still lower than that of the mutant enzyme V231A/K382G (Fig. 3B). tryptophan synthase was reacted with different substrate concentrations of L-serine, and the mutant enzyme of tryptophan synthase V231A/K382G maintained high activity with L-serine $100 \mathrm{mmol} / \mathrm{L}$, while the optimal concentration of L-serine for the parental enzyme was approximately $40 \mathrm{mmol} / \mathrm{L}$ (Fig. 3C). The molar concentration ratio of serine to 5hydroxyindole was 1:1. The optimal concentration of 5-hydroxyindole for the mutant enzyme was 100 $\mathrm{mmol} / \mathrm{L}$.

\section{Synthesis of L-5-hydroxytryptophan}

L-5-Hydroxytryptophan was synthesized by the mutant enzyme V231A/K382G at L-serine $100 \mathrm{mmol} / \mathrm{L}$, $35^{\circ} \mathrm{C}$ and $\mathrm{pH}$ 8.5. The reactants were collected at $1 \mathrm{~h}, 2 \mathrm{~h}, 4 \mathrm{~h}$ and $15 \mathrm{~h}$. The content of the product L-5hydroxytryptophan was determined by an amino acid analyser (L-8900, Japan). The content of L-5hydroxytryptophan increased with reaction time (Fig. 4). After the reaction, activated carbon was added to the reaction liquid. The filtrate was concentrated and crystallized, and the crystals were separated by centrifugation. The infrared spectrum of L-5-hydroxytryptophan is shown in figrue 5 , with the introduction 
of amino (3400-3500 $\left.\mathrm{cm}^{-1}\right)$ and carboxyl groups (1650-1740 $\left.\mathrm{cm}^{-1}\right)$. L-5-hydroxytryptophan: m.p. $270^{\circ} \mathrm{C}$ (decomp), $[\mathrm{a}]=-32.5^{\circ}\left(c=1, \mathrm{H}_{2} \mathrm{O}\right)$.

\section{Mutation analysis}

Chimera 1.13 was used to analyse the substrate channel space of tryptophan synthase (PDB: 2dh6), and it was found that the amino acid residues of tryptophan synthase at positions 231 and 382 were located in the loop formed by the substrate channel [24]. The amino acid residue at site 231 was mutated from valine to alanine, and the residue at site 382 was mutated from lysine to glycine, which may change the folding direction of the loop, thus changing the size and shape of channel entrance and promoting mutated enzymatic activity (Fig. 6). The function of the $\beta$ subunit of tryptophan synthase (EC 4.2.1.20) is to use indole and L-serine to synthesize L-tryptophan [25-27]. Directed evolutionary molecular modification for the application of enzyme catalysis has achieved good results [28-29]. Tryptophan synthase from Pyrococcus furiosus has been modified by directed evolution and the engineered biocatalyst reacts with a variety of indole analogues and thiophenol [30]. An engineered variant of Pyrococcus furiosus tryptophan synthase provides an operationally simple and environmentally benign platform for preparation of $\beta$-branched tryptophan building blocks [31]. Directional evolution can reshape the active pocket to improve the substrate specificity of the enzyme and modify its substrate specificity. For a small active pocket, directional evolution can expand the active pocket to accommodate larger substrate molecules. At present, most studies have investigated tryptophan synthase derived from Pyrococcus furiosus, but the enzyme activity of this tryptophan synthase is low. The literature has reported that the substrates of tryptophan synthase derived from Salmonella include indole derivatives substituted with fluorine, chlorine, bromine and iodine, which can synthesize L-tryptophan derivatives [32]. In this study, L-5-hydroxytryptophan was synthesized by a modified tryptophan synthase. Tryptophan synthase was modified by error-prone PCR. A high-activity mutant enzyme (V231A/K382G) was obtained by a high-throughput screening method.

\section{Conclusion}

A highly active mutant of tryptophan synthase was obtained by directed evolution. The activity of mutant enzyme (V231A/K382G) is 3.79 times higher than that of its parent, and the mutant enzyme $(\mathrm{V} 231 \mathrm{~A} / \mathrm{K} 382 \mathrm{G})$ has good catalytic efficiency $\left(k_{\mathrm{cat}} / K_{\mathrm{m}}\right)$ of $4.36 \mathrm{mM}^{-1} \cdot \mathrm{s}^{-1}$. The conditions for L-5hydroxytryptophan preparation by the mutated enzyme were an L-serine $100 \mathrm{mmol} / \mathrm{L}, 35^{\circ} \mathrm{C}$, pH of 8.5 for $15 \mathrm{~h}$, with the yield of L-5-hydroxytryptophan reaching $86.7 \%$. Directed evolution is an effective strategy to increase the catalytic activity of tryptophan synthase.

\section{Declarations}

Ethical Approval Compliance with Ethical Standards.

Consent to Participate Not applicable. 
Consent to Publish Not applicable.

Author contributions LSX conceived and carried out experimental work and drafted the manuscript. TTL, BLJand ZYH contributed to data interpretation and reviewed and edited the manuscript. QC ang QXX conceived and supervised experimental work, secured funding, and edited the manuscript.

Funding This work was supported by Natural Science Research Project in Anhui Province (KJ2020A0729). Project of Suzhou University (2018XJXS02; 2019XJSN05; 2019XJZY10), Research Project in Suzhou university (2019ykf13, 2019YKF14). Open Fund project of National Engineering Laboratory ( NEL-SCRT 002).

Competing Interests The authors declare that they have no conflicts of interest.

\section{Availability of data and materials}

The datasets used and/or analysed in the current study are available from the corresponding author upon reasonable request.

\section{References}

1. Horvath, G.A., Meisner, L., Selby, K., Stowe, R., Carleton, B. (2017). Improved strength on 5hydroxytryptophan and carbidopa in spinal cord atrophy. Journal of Neurological Sciences, 378, 5962.

2. Gendle, M.H., Young, E.L., Romano, A.C. (2013). Effects of oral 5-hydroxytryptophan on a standardized planning task: insight into possible dopamine/serotonin interactions in the forebrain. Human Psychopharmacology Clinical Experimental, 28, 270-273.

3. Jangid, P., Malik, P., Singh, P., Sharma, M., Gulia, A.D. (2013). Comparative study of efficacy of L-5hydroxytryptophan and fluoxetine in patients presenting with first depressive episode. Asian Journal of Psychiatry, 6, 29-34.

4. Ohgi, Y., Futamura, T., Tetsuro, K., Kenji, H. (2013).Effects of antidepressants on alternations in serum cytokines and depressive-like behavior in mice after lipopolysaccharide administration. Pharmacology Biochemistry Behavior, 103, 853-859.

5. Feng, J. (2013). Isolation and purification of 5-hydroxytryptophan in extract from seeds of Griffonia simplicifolia by ion-exchange resin. Chinese Traditional Herbal Drugs, 44, 2410-2416.

6. Ye, L., Hu, Z., Du, G., Zhang, J., Dong, Q., Fu, F., Tian, J. (2012). Antidepressant-like effects of the extract from Cimicifuga foetida L. Journal of Ethnopharmacology, 144, 683-691.

7. Wang, H., Liu, W., Shi, F., Huang, L., Lian, J., Qu, L., Cai, J., Xu, Z. (2018). Metabolic pathway engineering for high-level production of 5-hydroxytryptophan in Escherichia coli. Metabolic Engineering, 48, 279-287.

8. Xu, D., Fang, M.J., Wang, H.J., Huang, L., Xu, Q.Y., Xu, Z.N. (2020).Enhanced production of 5hydroxytryptophan through the regulation of L-tryptophan biosynthetic pathway. Applied 
Microbiology Biotechnology, 104, 2481-2488.

9. Vasilescu, C., Todea, A., Nan, A., Circu, M., Turcu, R., Benea, I.-C., Peter, F. (2019). Enzymatic synthesis of short-chain flavor esters from natural sources using tailored magnetic biocatalysts. Food Chemistry, 296, 1-8.

10. Wang, H.Q., Jia, C.S., Xia, X., Karangwa, E., Zhang, X.M. (2018). Enzymatic synthesis of phytosteryl lipoate and its antioxidant properties. Food Chemistry, 240, 736-742.

11. Zhang, Y., Akoh, C.C. (2020). Enzymatic synthesis of L-o-galloylglycerol: Characterization and determination of its antioxidant properties. Food Chemistry, 305, 1-9.

12. Xu, G., Zhao, Q., Huang, B., Zhou, J.H., Cao, F.X. (2018). Directed evolution of a penicillin V acylase from Bacillus sphaericus to improve its catalytic efficiency for 6-APA production. Enzyme Microbial Technology, 119, 65-70.

13. Zhu, L., Wu, Z., Jin, J-M., Tang, S-Y. (2016). Directed evolution of leucine dehydrogenase for improved efficiency of L-tert-leucine synthesis. Applied Microbiology Biotechnology, 100, 5805-5813.

14. Han, H.W., Ling, Z.M., Khan, A., Virk, A.K., Kulshrestha, S., Li, X.K. (2019). Improvements of thermophilic enzymes: From genetic modifications to applications. Bioresource Technology,279, 350361.

15. Tian, K.Y., Tai, K., Chua, B.J.W., Li, Z. (2017). Directed evolution of Thermomyces lanuginosus lipase to enhance methanol tolerance for efficient production of biodiesel from waste grease. Bioresource Technology, 245, 1491-1497.

16. Zhang, Z.G., Yi, Z.L., Pei, X.Q., Wu, Z.L. (2010). Improving the thermostability of Geobacillus stearothermophilus xylanase XT6 by directed evolution and site-directed mutagenesis. Bioresource Technology, 101, 9272-9278. https://doi.org/10.1016/j.biortech.2010.07.060.

17. Chen, Z.M., Ma, Y.H., He, M.Y., Ren, H.Y., Zhou, S., Lai, D.Y., Wang, Z.G., Jiang, L.S. (2015). Semirational directed evolution of monoamine oxidase for kinetic resolution of rac-mexiletine. Applied Biochemistry and Biotechnology, 176, 2267-2278.

18. Luo, , Ma, J.W., Chang, Y.H., Yu, H.M., Shen Z.Y. (2016). Directed evolution and mutant characterization of nitrilase from rhodococcus rhodochrous tg1-A6. Applied Biochemistry and Biotechnology, 178(8):1510-1521.

19. Chen, Y.Q., Zhang, B., Pei, H.L., Lv, J.N., Yang, W.H., Cao, Y.H., Dong (2012) Directed evolution of Penicillium janczewskii zalesk a-galactosidase toward enhanced activity and expression in Pichia pastoris. Applied Biochemistry and Biotechnology, 168(3):638-650.

20. Xu, L.S., Wang, Z.Y., Mao, P.T., Liu, J.Z., Zhang, H.J., Liu, Q., Jiao, Q.C. (2013). Enzymatic synthesis of S-phenyl-L-cysteine from keratin hydrolysis industries wastewater with tryptophan synthase. Bioresource Technology, 133, 635-637.

21. Xu, L.S., Zhang, X.T., Gao, G.Z., Yue, S. (2019). Highly efficient preparation of active S-phenyl-Lcysteine with tryptophan synthase using a chemoenzymatic method. BMC biotechnology, 19, 1-8.

22. Zhao, G.H., Liu, J.Z., Dong, K., Zhang, F., Zhang, H.J., Liu, Q.,Jiao, Q.C. (2011). Enzymatic synthesis of L-tryptophan from hair acid hydrolysis industries wastewater with tryptophan synthase, Bioresource 
Technology, 102, 3554-3557.

23. Mu, D., Lu, J., Shu, C., Li, H., Li, X., Cai, J., Luo, S., Yang, P., Jiang, S., Zheng, Z. (2018). Improvement of the activity and thermostability of microbial transglutaminase by multiple-site mutagenesis. Bioscience Biotechnology and Biochemistry, 82, 106-109.

24. Nishio, K., Ogasahara, K., Morimoto, Y., Tsukihara, T., Lee, S.J., Yutani, K. (2010). Large conformational changes in the Escherichia coli tryptophan synthase beta(2) subunit upon pyridoxal 5'-phosphate binding. FEBS J, 277, 2157-2170.

25. Bornscheuer, U.T., Pohl, M. (2001). Improved biocatalysts by directed evolution and rational protein design. Current Opinion in Chemical Biology, 5, 137-143. 25. Dierkers, A.T., Niks, D., Schlichting, I., Dunn, M.F. (2009). Tryptophan synthase: structure and function of the monovalent cation site. Biochemistry, 48, 10997-11010.

26. Watkins-Dulaney, E. J., Straathof, S., Arnold, F.H. (2020). Tryptophan synthase: biocatalyst extraordinaire. ChemBioChem, 22, 1-12.

27. Lai,J.F., Niks, D., Wang,Y.C., Domratcheva, T., Barends, T.R.M., Schwarz, F., Olsen, R.A., Elliott, D.W., Fatmi, M.Q., Chang, C.A., Schlichting, I., Dunn, M.F., Mueller, L.J. (2011). X-ray and NMR crystallography in an enzyme active site: the indoline quinonoid intermediate in tryptophan synthase. Journal of the American Chemical Society, 133, 4-7.

28. Evran, S., Telefoncu A., Sterner R. (2012). Directed evolution of $(\beta a)_{8}$-barrel enzymes: establishing phosphoribosylanthranilate isomerisation activity on the scaffold of the tryptophan synthase asubunit. Protein Engineering, Design Selection, 25, 285-293.

29. Buller, A.R., Roye, P., Cahn, J.K.B., Scheele, R.A., Herger, M., Arnold, F.H. (2018). Directed evolution mimics allosteric activation by stepwise tuning of the conformational ensemble. Journal of the American Chemical Society, 140,7256-7266.

30. Herger, M., Roye, P. V., Romney, D.K., Brinkmann-Chen, S., Buller, A.R., Arnold. F.H. (2016) Synthesis of $\beta$-branched tryptophan analogues using an engineered subunit of tryptophan synthase. Journal of the American Chemical Society, 138(27), 8388-8391.

31. Boville, C.E., Scheele, R.A., Koch, P., Brinkmann-Chen, S., Buller, A.R., Arnold, F.H. Engineered biosynthesis of $\beta$-alkyl tryptophan analogs. Angewandte Chemie International Edition, 57(45), 14764 14768.

32. Smith, D.R.M., Willemse, T., Gkotsi, D.S., Schepens, W., Maes, B.U.W., Ballet, S., Goss, R.J.M. (2014) . The first one-pot synthesis of L-7-iodotryptophan from 7-iodoindole and serine, and an improved synthesis of other L-7-halotryptophans. Organic Letters, 16, 2622-2625.

\section{Figures}




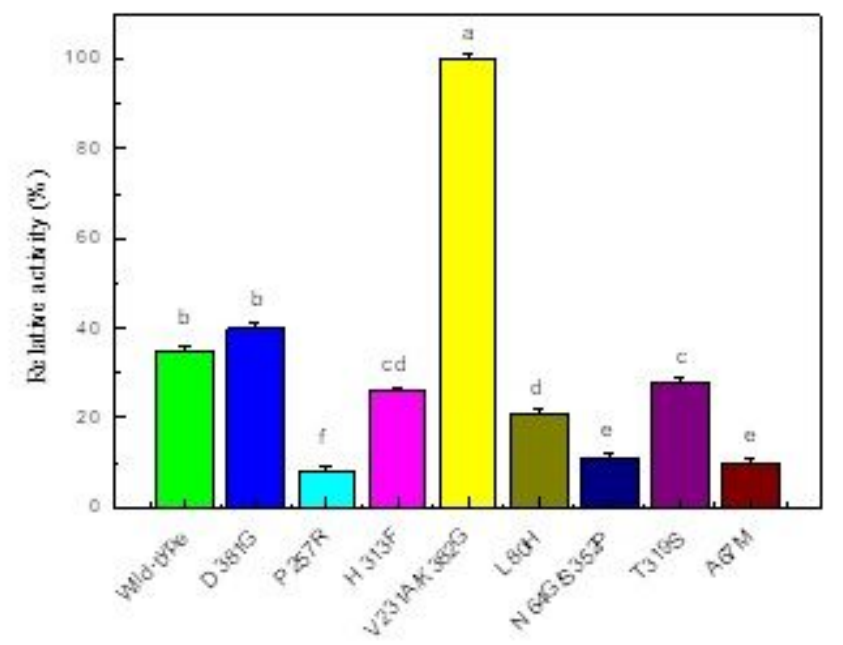

\section{Figure 1}

Relative activities of the mutants of tryptophan synthase. The reaction conditions for the mutated enzyme were an L-serine concentration of $100 \mathrm{mmol} / \mathrm{L}$, a reaction temperature of $35^{\circ} \mathrm{C}$, and a pH of 8.5 for $15 \mathrm{~h}$. The meaning of different letters in the figure legend indicates significant differences.

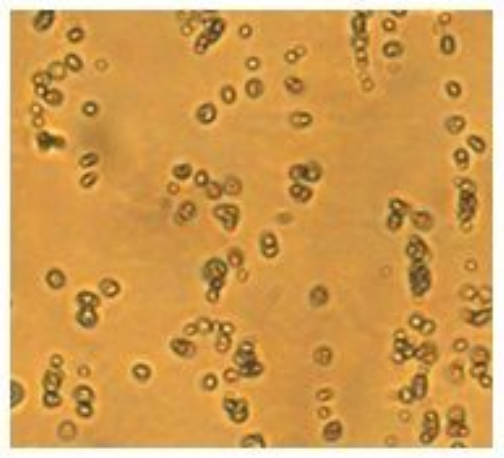

A

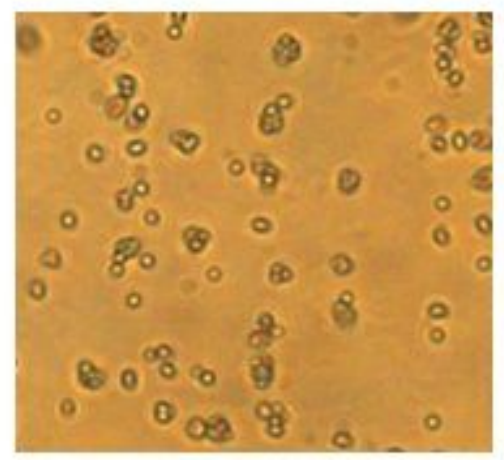

$\mathrm{C}$

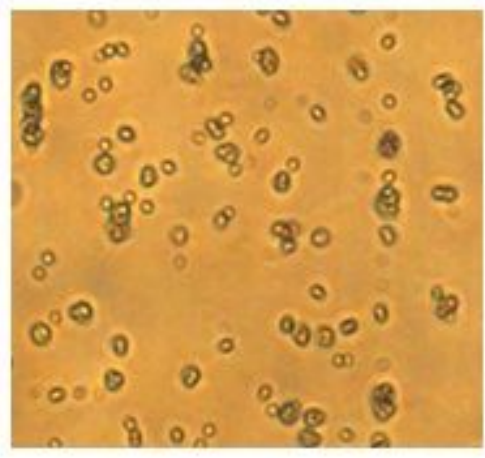

B

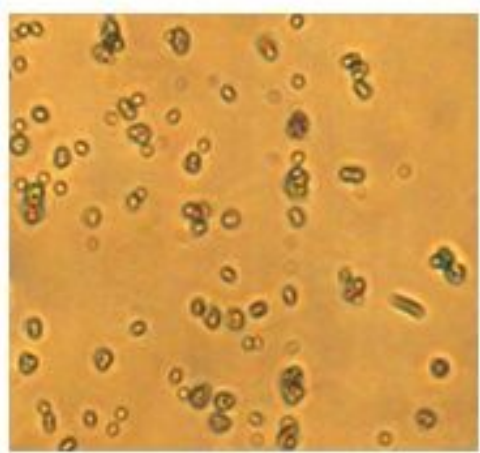

$\mathrm{D}$

Figure 2 
Microbial morphology of the mutants of tryptophan synthase. (A: Wild-type strain; B:V231A/K382G; C:D381G; D:T319S)

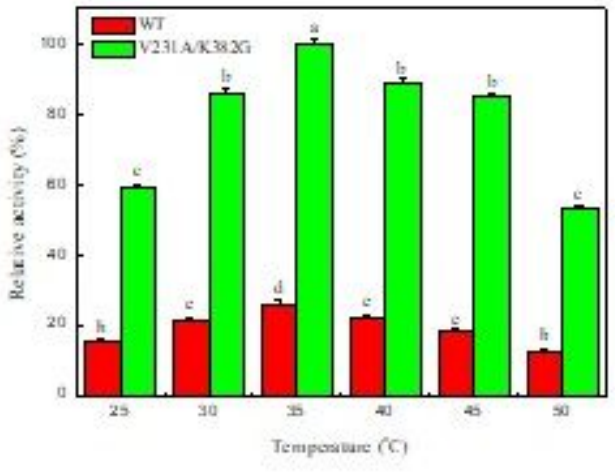

A

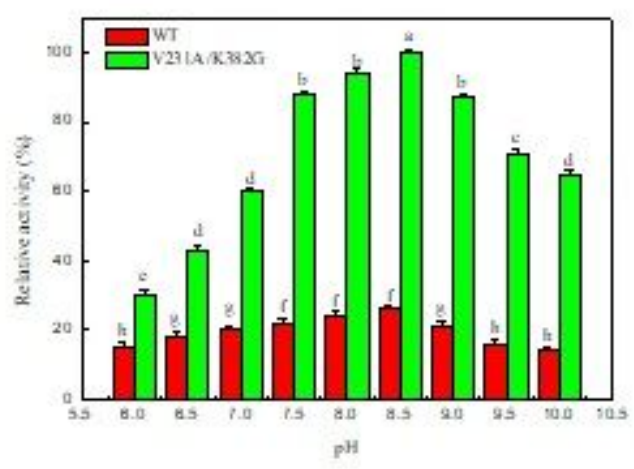

B

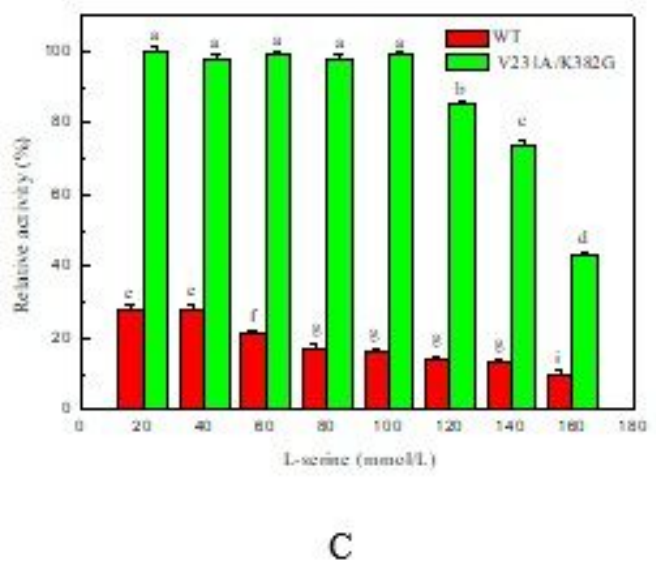

Figure 3

Effects of temperature, $\mathrm{pH}$, and L-serine on the activity of the tryptophan synthase mutant. A:The reaction conditions for the mutated enzyme were an L-serine concentration of $100 \mathrm{mmol} / \mathrm{L}$ and a pH of 8.5 for 15 $\mathrm{h}$. B:The reaction conditions for the mutated enzyme were an $\mathrm{L}$-serine concentration of $100 \mathrm{mmol} / \mathrm{L}$ at $35^{\circ} \mathrm{C}$ for $15 \mathrm{~h}$. C: The reaction conditions for the mutated enzyme were $35^{\circ} \mathrm{C}$ at pH of 8.5 for $15 \mathrm{~h}$. The meaning of different letters in the figure legend indicates significant differences. 


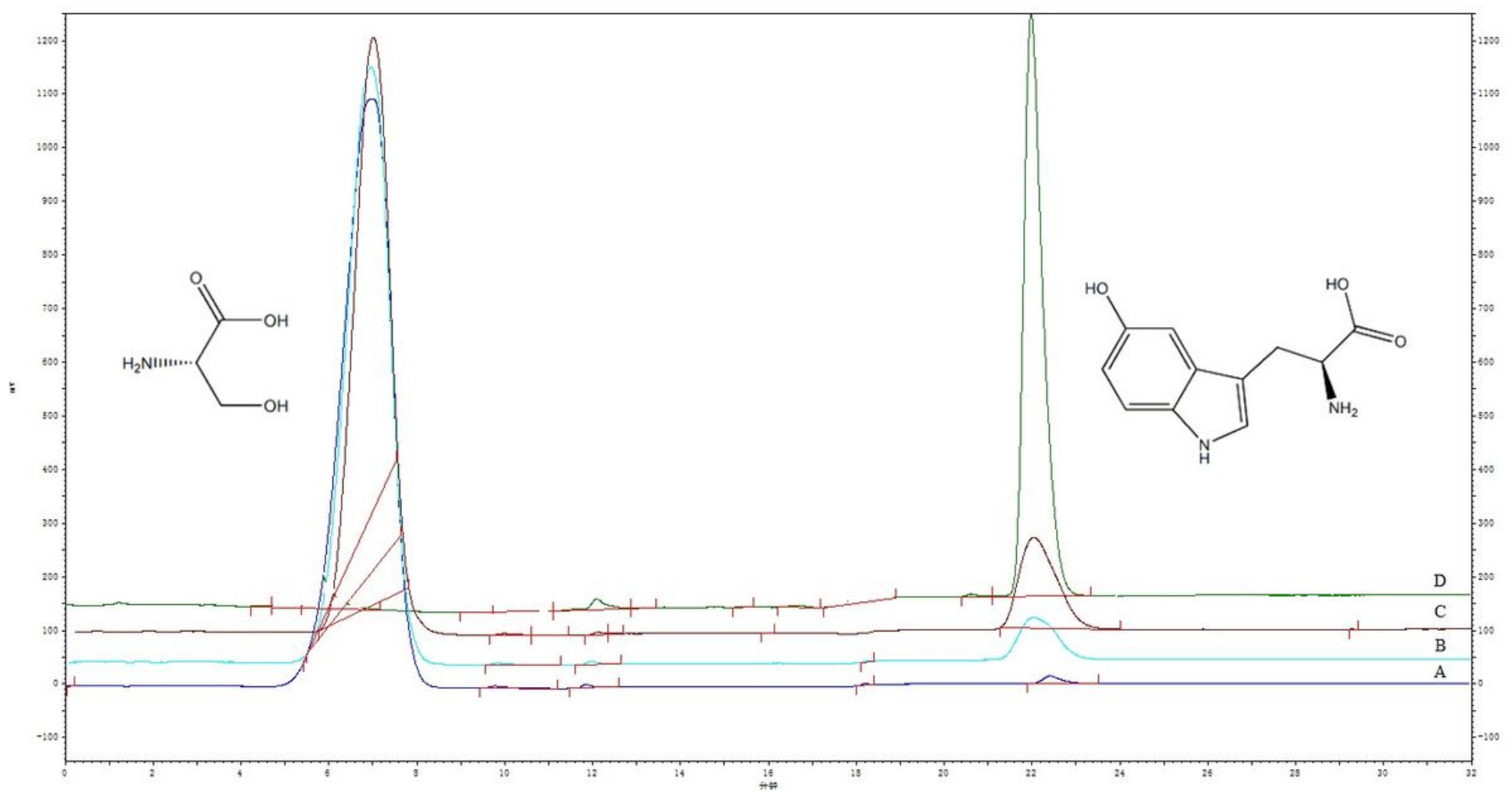

Figure 4

Synthesis of L-5-hydroxytryptophan by the mutated tryptophan synthase (V231A/K382G). (A: 1 h; B: 2 h; C: $4 \mathrm{~h} ; \mathrm{D}: 15 \mathrm{~h}$ ). The reaction conditions for the mutated enzyme were an L-serine concentration of 100 $\mathrm{mmol} / \mathrm{L}$, a reaction temperature of $35^{\circ} \mathrm{C}$, and a $\mathrm{pH}$ of 8.5 .

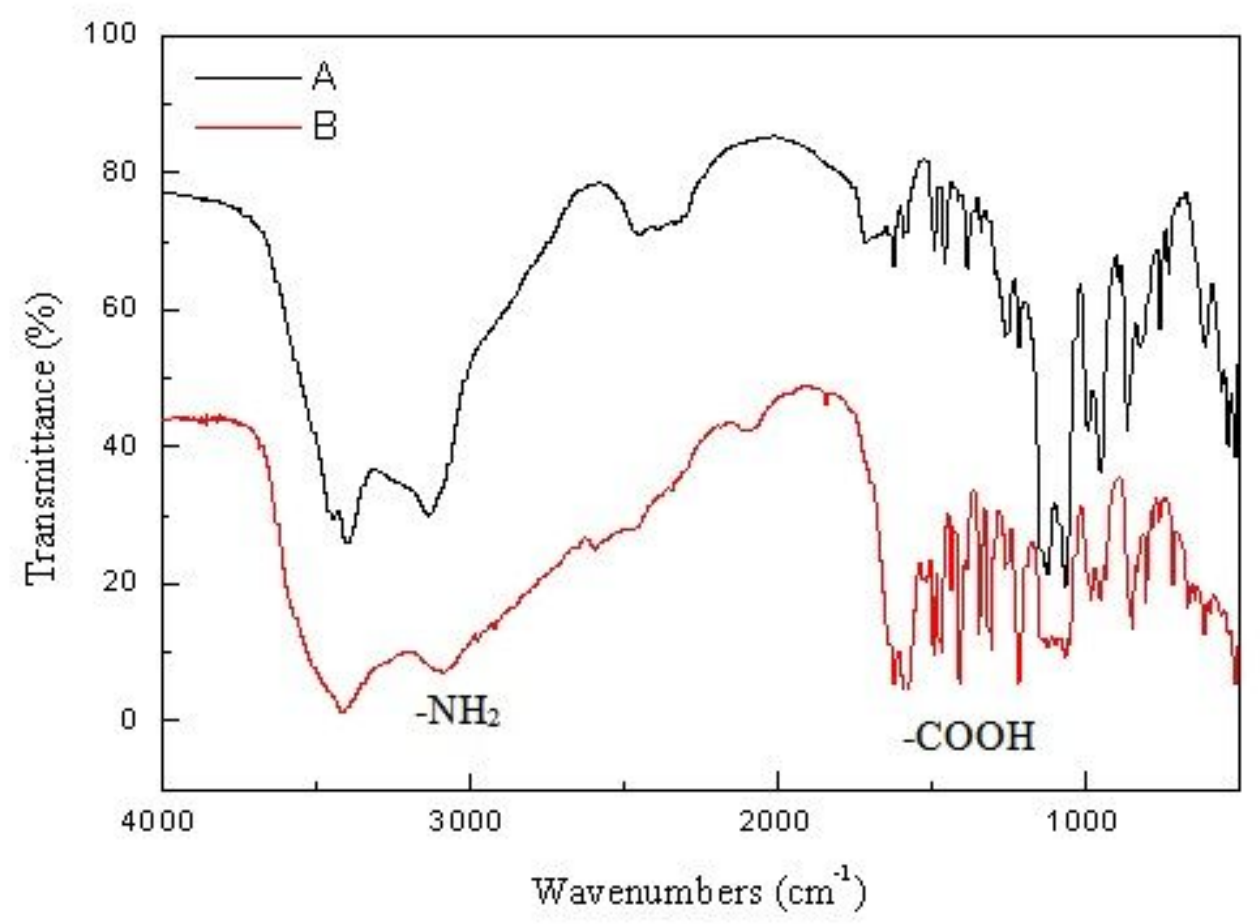

Figure 5 
FTIR spectra of (B) L-5-hydroxytryptophan and (A) 5-hydroxyindole.
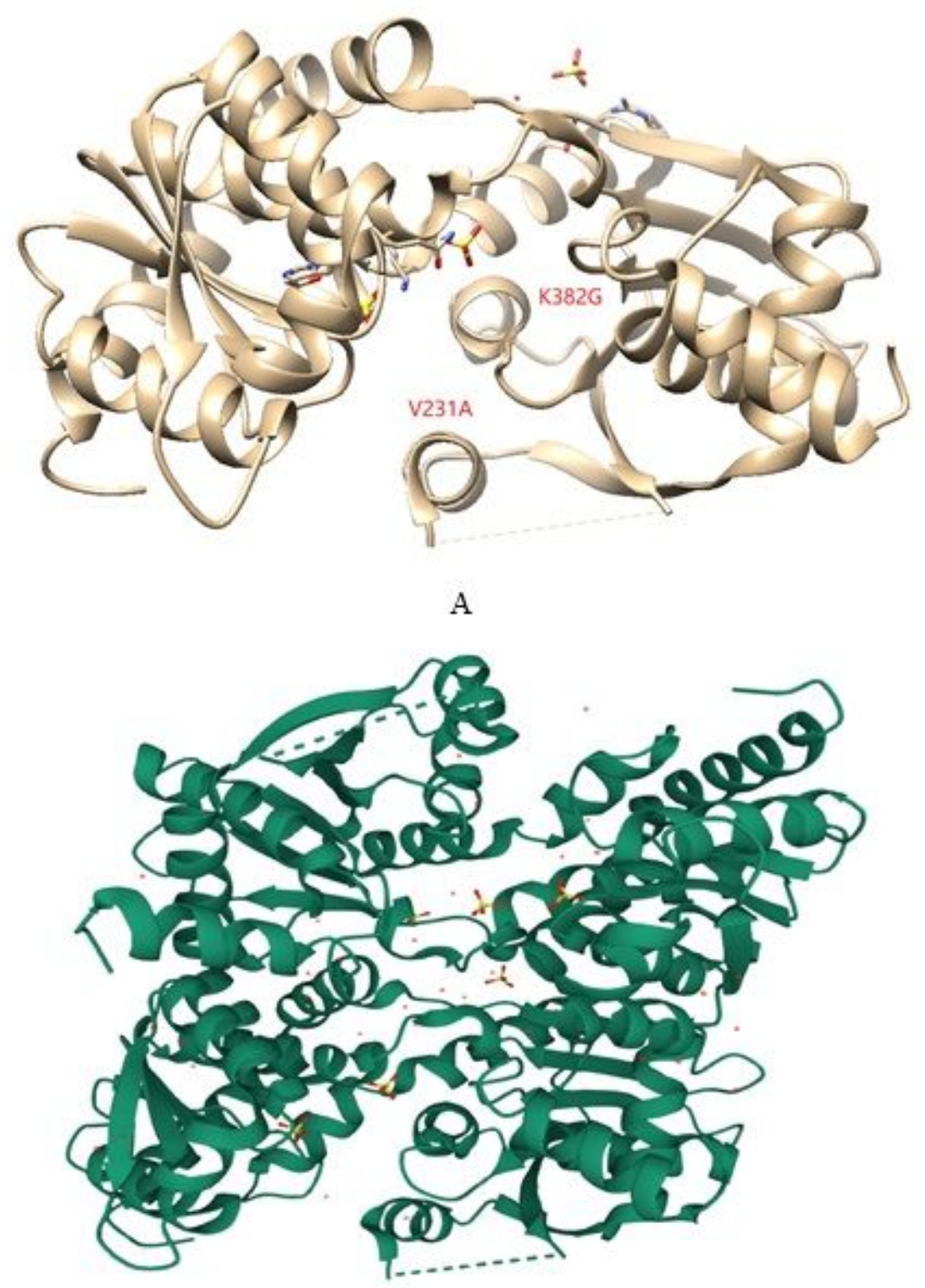

B

\section{Figure 6}

Relationship between the substrate channel and the binding sites of residues 231 and 382 in the mutant (A). The structure of the tryptophan synthase wild type (B). 